\title{
The emerging role of CXCL10 in cancer (Review)
}

\author{
MINGLI LIU, SHANCHUN GUO and JONATHAN K. STILES \\ Department of Microbiology, Biochemistry and Immunology, Morehouse School of Medicine, Atlanta, GA, USA
}

Received December 10, 2010; Accepted April 20, 2011

DOI: 10.3892/ol.2011.300

\begin{abstract}
The chemokine interferon- $\gamma$ inducible protein $10 \mathrm{kDa}$ (CXCL10) is a member of the CXC chemokine family which binds to the CXCR3 receptor to exert its biological effects. CXCL10 is involved in chemotaxis, induction of apoptosis, regulation of cell growth and mediation of angiostatic effects. CXCL10 is associated with a variety of human diseases including infectious diseases, chronic inflammation, immune dysfuntion, tumor development, metastasis and dissemination. More importantly, CXCL10 has been identified as a major biological marker mediating disease severity and may be utilized as a prognostic indicator for various diseases. In this review, we focus on current research elucidating the emerging role of CXCL10 in the pathogenesis of cancer. Understanding the role of CXCL10 in disease initiation and progression may provide the basis for developing CXCL10 as a potential biomarker and therapeutic target for related human malignancies.
\end{abstract}

\section{Contents}

1. Introduction

2. CXCL10 gene structure, function and signaling pathways

3. CXCL10 gene and cancer types

4. Conclusions

\section{Introduction}

Chemokines are small, structurally related proteins which play a significant role in leukocyte trafficking (1) by producing chemotactic activity in cells expressing corresponding chemokine receptors. Based on the position of the first two conserved cysteine residues within the $\mathrm{N}$-terminal, the chemokines are divided into two major (CX3C and $\mathrm{CXC}$ ) and two minor (CC and C) subfamilies (2-4). The CX3C subfamily has three

Correspondence to: Dr Mingli Liu and Dr Jonathan Stiles, Department of Microbiology, Biochemistry and Immunology, Morehouse School of Medicine, 224 MEB Building, 720 Westview Drive SW, Atlanta, GA 30310, USA

E-mail:mliu@msm.edu

Key words: chemokine, CXCL10, cancer intervening residues separating the two N-terminal cysteines, whereas the CXC subfamily only has one non-conserved amino acid residue separating the $\mathrm{N}$-terminal cysteines. $\mathrm{CC}$ chemokines are those in which two cysteines are adjacent to each other, and a single known $\mathrm{C}$ chemokine lacks the first cysteine of the N-terminal pair. CXCL10 is a member of the CXC subfamily. Target cells of chemokines express corresponding receptors to which chemokines bind and mediate function (5). Therefore, the receptors of $\mathrm{CC}$ and CXC chemokine are referred to as CCRs and CXCRs, respectively. $\mathrm{CC}$ chemokines bind to $\mathrm{CC}$ chemokine receptors, and CXC chemokines bind to $\mathrm{CXC}$ chemokine receptors. Most receptors usually bind to more than one chemokine, and most chemokines usually bind to more than one receptor. CXCL10 specifically activates a receptor, CXCR3, which is a seven trans-membrane-spanning $G$ protein-coupled receptor (6) predominantly expressed on activated $\mathrm{T}$ lymphocytes (Th1) (7), natural killer (NK) cells, inflammatory dentritic cells, macrophages and B cells $(8,9)$. The interferon-induced angiostatic CXC chemokines, monokine induced by interferon (Mig/CXCL9) and interferon-inducible T-cell chemoattractant (I-TAC/CXCL11), also activate CXCR3. These CXC chemokines are preferentially expressed on Th1 lymphocytes $(6,10,11)$.

Under proinflammatory conditions CXCL10 is secreted from a variety of cells, such as leukocytes, activated neutrophils, eosinophils (12), monocytes, epithelial cells, endothelial cells, stromal cells (fibroblasts) and keratinocytes in response to IFN- $\gamma(13,14)$. This crucial regulator of the interferon response, preferentially attracts activated Th1 lymphocytes to the area of inflammation and its expression is associated with Th1 immune responses (15-17). CXCL10 is also a chemoattractant for monocytes, T cells and NK cells.

CXCL10 is highly expressed in a diverse range of human diseases. It has been shown to be involved in the pathological processes of three main human disorders, infectious diseases, inflammatory (18-20) and autoimmune diseases (2), and cancer. Since CXCL10 plays a significant role in leukocyte homing to inflamed tissues, it exacerbates inflammation and causes significant tissue damage (2). Additionally, the CXC chemokines are a unique family of cytokines that either stimulate or inhibit angiogenesis depending on the presence of the structural domain of Glu-Leu-Arg; an ELR motif. CXCL10 is an ELR-negative CXC chemokine that attenuates angiogenesis and has anti-tumor actions (21-23). However, an increased expression of CXCL10 and its corresponding receptor CXCR3 have also been associated with advanced human cancers, including 
malignant melanoma (24), ovarian carcinoma (25), multiple myeloma (26), B-cell lymphoma (27) and basal cell carcinoma (14). In the central nervous system (CNS), microglia, astrocytes and even neurons express and secrete soluble CXCL10 $(28,29)$. CXCL10 chemoattracts microglia cells into the circulation of CNS. CXCL10 and its receptor CXCR3 play a role in both peripheral and various CNS pathologies since the interference of CXCL10/CXCR3 signaling alters the initiation and progression in various CNS disease models $(29,30)$. The increased production of CXCL10 in CNS has been associated with cerebral ischemia, epilepsy, brain inflammation and a number of neurodegenerative diseases such as multiple sclerosis (MS), Alzheimer's disease, amyotrophic lateral sclerosis, and human immunodeficiency virus encephalitis (29). The aim of this reiew is to focus mainly on the current understanding of the role of CXCL10 in cancer.

\section{CXCL10 gene structure, function and signaling pathways}

The human CXCL10 gene, was initially isolated in 1985 by Luster et al (31) while treating a lymphoma cell line (U937) with recombinant IFN- $\gamma$. CXCL10 cDNA has an open reading frame of $1,173 \mathrm{bp}$ containing 4 exons and encoding a protein of 98 amino acids with a molecular mass of 10,000 dalton. The primary translation product of CXCL10 is a $12-\mathrm{kDa}$ protein and constitutes two internal disulfide cross bridges (13). The predicted signal peptidase cleavage generates a $10-\mathrm{kDa}$ secreted polypeptide with four conserved cysteine residues in the N-terminal (13). The CXCL10 gene localizes on chromosome 4 at band q21, a locus associated with an acute monocytic/ B-lymphocyte lineage leukemia exhibiting translocation of $\mathrm{t}(4 ; 11)$ (q21; q23). The CXCL10 protein shows significant homology in sequence with a family of proteins having chemotactic (platelet factor $4, \beta$-thromboglobulin) and mitogenic (connective tissue-activating peptide $\mathrm{HI}$ ) activities, which are associated with inflammation and cell proliferation $(13,32)$. Human CXCL10 has a 63\% homology in cDNA sequence with mouse CXCL10.

As with other chemokines, CXCL10 is a structurally specific protein, in which the potency and biological activities vary as a result of structural differences. The monomeric structure of CXCL10 exhibits a typical chemokine fold consisting of a three-stranded $\beta$ sheet overlaid by an $\alpha$ helix with a number of the receptor binding residues located in the associated loops stabilized by the disulfide bonds (3). A monomeric variant structure of CXCL10 was found by nuclear magnetic resonance spectroscopy. This new variant showed that the regions of the N-terminal and 40s loops within the CXCL10 molecule interplay with each other and form a hydrophobic cleft. This unusual structural characteristic of CXCL10 provides an explanation for the ability of CXCL10 to bind to both CXCR3 and CCR3 receptors (33). Another stereotypical oligomerization of CXCL10 provides an additional source of structural diversity (3) which is essential for CXCL10 to recruit activated T cells that bind to endothelial cells and subsequently trans-migrate in vivo (34). This hypothesis was supported by Campanella et al (34), who determined that CXCL10 knockout mice lose their ability to recruit activated CD8+ T cells into their airways due to the presence of the $\mathrm{N}$-methyl group disrupting the interaction of hydrogen bonds between the main chains, preventing the formation of dimers and oligomerization. In vitro, the N-methylated Leu27 monomeric mutants were capable of inducing CXCR3 internalization and the chemotaxis of CD8+ T cells expressing CXCR3, but this induction required at least ten times higher concentrations than wild-type CXCL10; heparin and CXCR3 binding were noted, but at greatly reduced efficacy. These results indicate that, in vitro, a considerably higher concentration of monomer mutant CXCL10 ligand is required to bind receptor CXCR3 and heparin (34). In an experiment designed by Swaminathan et al (3), CXCL10 molecules were found to exist in three different crystal forms: monomer, dimer and tetramer. In free solution, CXCL10 exists in monomer-dimer equilibrium, and tetrameric structures may represent species promoted by the binding of glycosaminoglycans (GAG). Findings of these authors suggest that only oligomeric forms of CXCL10 bind to endothelial and epithelial cells in a GAG-dependent manner (3). In agreement with the results of Swaminathan et al, a novel tetramer in the mouse CXCL10 structure has been discovered where two typical CXC chemokine dimers bind to their N-terminal regions to form a tetrameric assembly (35). Furthermore, the free N-terminal areas of two molecules at each terminal of the tetramer, enhance the probability of further attachment of molecules to generate higher order oligomers that may have functional relevance (35). The study by Jabeen et al (35) greatly contributes to the theory that the existence of CXCL10 in different oligomeric forms is crucial for its in vivo activity.

Functionally, CXCL10 exerts its biological effects by binding to CXCR3, and by inducing signaling effects in a paracrine or autocrine manner (14). CXCL10 induction depends predominantly on the carboxyl-terminal region of CXCR3, which is essential for CXCR3 internalization, chemotaxis and calcium mobilization induced by the CXCL10 ligand $(8,36)$.

Regulation of CXCR3+ cell chemotaxis. CXCL10 performs 'homing' functions to chemoattract CXCR3-positive cells, including macrophages [microglia cell in CNS (37-39)], dendritic cells, NK cells and activated $\mathrm{T}$ lymphocytes (CD4+ T cells and CD8+ T cells) towards inflammatory, infectious and neoplastic regions. Consequently, CXCL10 isinvolved in modulating both innate and adaptive immunity, inducing tissue damage and contributing to tumorigenesis (37-39).

Induction and variation in the conditions for CXCL10 induced apoptosis. Using an in vitro model of cultured cortical neurons, neuronal CXCL10 expression recruits glial cells during embryogenesis, indicating that CXCL10 may be involved in apoptosis during the development of the nervous system $(29,40)$. Alternatively, CXCL10 has been shown to facilitate cellular clearance of myeloid cells and strengthen the interaction between glial cells and neurons, which is a crucial step for synaptogenesis in the later stages of development of the nervous system (29). CXCL10 also significantly increased the apoptotic rate of cancer cells in cervical carcinoma (41).

Promotion of cell growth and proliferation (14). CXCL10, along with other CXC chemokines, binds to G-protein coupled receptors and induces a wide spectrum of biological and physiological activities. One of these activities involves the increase of cell growth and proliferation. CXCL10 coloca- 
lizes with the cell proliferation marker, cytokeratin 17 (K17) in tumor cells (14), whose proliferating actions are cell cycle dependent (42).

CXCL10 appears to have dual effects on cell growth. The proliferative or anti-proliferative action of CXCL10 appears to be cell-type-dependent; in other words, it may depend on the subtype of its receptor CXCR3. There are three CXCR3 splice variants: CXCR3-A, CXCR3-B and CXCR3-alt. Different cell types demonstrate various expression patterns. Additionally, various isoforms of CXCR3 induce the opposing actions of CXCL10 on proliferation. The main isoform, known as CXCR3-A, found in most cell types, codes for a protein of 368 amino acids (42) and couples with Gai to activate the ERK1/2, p38/MAPK, JNK and PI3-kinase/Akt signaling pathways, thereby inducing intracellular calcium influx, DNA synthesis and cell proliferation or chemotaxis (8,42-44). These types of cells include normal human bronchial epithelial cells (42), astrocytes, glioma cells (44), microglia cells (45), MDA-MB-231 breast cancer cells (46) and basal cell carcinoma (14). CXCR3-alt, which is known to co-express with CXCR3-A at a very low level $(14,42)$, has not been found to be involved in cell growth.

Inhibition of cell growth and proliferation. The antiproliferative action of CXCL10 is regulated by a variant isoform, CXCR3-B. CXCR3-B codes for a larger protein of 416 amino acids, couples with Gas to activate adenylyl cyclase and causes the inhibition of endothelial cell proliferation and migration $(43,47,48)$. This appears to be the key mechanism by which CXCL10 exerts its antiproliferative activity. This receptor subtype does not induce chemotaxis $(43,47)$. These types of cells are included in uterine endometrial cancer $(46,49)$, glioblastoma (37), CCL-51 mammary tumor $(50,51)$ and colorectal cancer (53). CXCR3+ T-cell migration into inflammatory and neoplastic regions attracted by CXCL10 along with CXCL9 and CXCL11 also contributes to anti-tumor progression and anti-metastasis (37). The variant CXCR3-B as a common receptor for all four angiostatic chemokines (CXCL4, CXCL9, CXCL10 and CXCL11) has enabled a better understanding of the role of CXC chemokines in the sequential participation of inflammatory cells and in the regulation of the inflammatory reaction resulting in angiostasis, and the inhibition of endothelial cell proliferation (53).

Regulating angiostatic action. CXC chemokines have dual effects on angiogenesis, depending on the presence of the Glu-Leu-Arg (ELR) motif. This well-established antiproliferative (angiostatic) function, particularly on endothelial cells by CXCL10, has been shown to be regulated by the ELR motif. ELR-negative CXCL10 is an angiostatic chemokine that inhibits angiogenesis and is associated with its anti-tumor activities (21-23).

CXCL10 has cross talk with various typical signaling pathways. In breast cancer, Ras-induced CXCL10 overexpression is mediated through the Raf and PI3K signaling pathways, which may contribute to the development of breast tumors through cancer cell proliferation (46). In microglia cells, elevated CXCL10 expression occurs through p38/MAPK, JNK/MAPK and NF- $\kappa \mathrm{B}$ cascades (45). In human airway epithelial cells, $\mathrm{p} 38$ /MAPK and PI3K signaling play a significant role in CXCL10/CXCR3 chemokine receptor-induced chemotaxis (54). In murine macrophage-like cells, activation of JAK1, JAK2/STAT1, but not the p38 pathway, up-regulates the expression of CXCL10, which is a strong inflammatory factor (55). The inhibition of CXCL10 expression in the cells by targeting the JAK/STAT1 signaling pathway may exert anti-inflammatory effects by attenuating the formation of chemokine CXCL10. Rabies virus (RV) stimulates CXCL10 expression in macrophages by activating extracellular signalregulated kinases 1 and 2 (ERK1/2) (56). The RV-induced expression of CXCL10 in microglia in CNS was achieved by the activation of $\mathrm{p} 38$ and $\mathrm{NF}-\kappa \mathrm{B}$ pathways (57).

\section{CXCL10 gene and cancer types}

Interactions between chemokines and chemokine receptors were recently proposed to be of importance in the initiation and progression of cancer. CXCL10 has dual actions on tumorigenesis depending on the spliced variant of the corresponding CXCR3 receptor. CXCR3-B possesses growthinhibitory properties, whereas CXCR3-A promotes cell proliferation (46).

Anti-tumor effects through angiostatic action. Various model systems have shown ELR-negative CXC chemokines to inhibit angiogenesis. In xenograft models of lymphoma, squamous cell carcinoma and adenocarcinoma of lung, the production of CXCL10 was inversely correlated with tumor growth, resulting in a marked reduction in tumor-associated angiogenesis. CXCL10 mediates its effects in T cell, macrophages- or NK-independent manner $(22,23)$. CXCL10 may effect the suppression of angiogenesis associated with fibroblast growth factor (bFGF) in advanced uterine endometrial cancers (49). CXCL10 inhibits the growth of cervical carcinoma by down-regulating the formation of microvessels, the expression of proliferating cell nuclear antigens and the expression of human papillomavirus oncoproteins E6 and E7 through an increase in the apoptotic rate (41). In estrogen receptorpositive $\left(\mathrm{ER}^{+}\right)$mammary tumors, CXCL10 inhibits vascular endothelial growth factor levels to reduce tumor burden (50).

Antitumor effects through immunogenic action. In the mouse glioblastoma model, CXCL10-mediated immunostimulation is likely to be responsible for the therapeutic efficacy rather than inhibiting vascularization(37). Immune modulation ofCXCL10 has been widely used to modify dendritic cells to increase vaccine potency. Numerous investigators have confirmed that the CXCL10 gene has significant synergistic effects against tumors through its immunomodulatory properties by recruiting immature antigen-presenting, dentritic or early activated $\mathrm{T}$ cells into the tumor in murine glioma and the melanoma model (58-60).

Okada (61) utilized CXCL10 as a homing factor for cytotoxic $\mathrm{T}$ lymphocytes with a type 1 phenotype (Tc1) to attract cytotoxic T cells into CNS tumors, where cells durably exert antitumor effects in the CNS tumor. This author used type 1 polarizing DCs loaded with glioma-associated antigen peptides in combination with polyinosinic-polycytidylic acid stabilized by lysine and carboxymethylcellulose (poly-ICLC) 
Table I. Comparative analysis of CXCL10 expression in various types of human cancers (Oncomine data).

\begin{tabular}{|c|c|c|c|c|c|}
\hline & \multirow[t]{2}{*}{ Fold change } & \multirow[t]{2}{*}{ P-value } & \multicolumn{2}{|c|}{ No. of samples } & \multirow[t]{2}{*}{ References } \\
\hline & & & Normal & Cancer & \\
\hline Bladder cancer & 3.039 & $6.79 \mathrm{E}-11$ & 48 & 81 & Sanchez-Carbayo et al, (69) \\
\hline Brain and CNS cancer & $\begin{array}{l}2.237 \\
4.971\end{array}$ & $\begin{array}{l}5.40 \mathrm{E}-12 \\
2.67 \mathrm{E}-4\end{array}$ & $\begin{array}{r}23 \\
3\end{array}$ & $\begin{array}{l}81 \\
84\end{array}$ & $\begin{array}{l}\text { Sun et al, (70) } \\
\text { Lee et al, (71) }\end{array}$ \\
\hline Breast cancer & $\begin{array}{l}19.021 \\
5.072\end{array}$ & $\begin{array}{l}8.00 \mathrm{E}-12 \\
1.71 \mathrm{E}-4\end{array}$ & $\begin{array}{r}7 \\
15\end{array}$ & $\begin{array}{r}40 \\
7\end{array}$ & $\begin{array}{l}\text { Richardson et al, (72) } \\
\text { Karnoub et al, (73) }\end{array}$ \\
\hline Cervical cancer & 4.009 & $2.32 \mathrm{E}-5$ & 22 & 20 & Pyeon et al, (74) \\
\hline Colorectal cancer & 2.547 & $2.13 \mathrm{E}-8$ & 41 & 50 & Ki et al, (75) \\
\hline Head and neck cancer & $\begin{array}{l}6.410 \\
14.448 \\
3.761 \\
3.073\end{array}$ & $\begin{array}{l}1.15 \mathrm{E}-11 \\
1.49 \mathrm{E}-4 \\
5.41 \mathrm{E}-4 \\
1.28 \mathrm{E}-6\end{array}$ & $\begin{array}{l}13 \\
22 \\
22 \\
28\end{array}$ & $\begin{array}{r}41 \\
6 \\
15 \\
31\end{array}$ & $\begin{array}{l}\text { Ginos et al, (76) } \\
\text { Pyeon et al, (74) } \\
\text { Pyeon et al, (74) } \\
\text { Talbot et al, (77) }\end{array}$ \\
\hline Kidney cancer & $\begin{array}{l}12.873 \\
5.447 \\
11.612 \\
5.897\end{array}$ & $\begin{array}{l}3.10 \mathrm{E}-12 \\
5.90 \mathrm{E}-8 \\
9.94 \mathrm{E}-11 \\
4.41 \mathrm{E}-7\end{array}$ & $\begin{array}{r}5 \\
10 \\
11 \\
11\end{array}$ & $\begin{array}{l}26 \\
10 \\
32 \\
27\end{array}$ & $\begin{array}{l}\text { Yusenko et al, (78) } \\
\text { Gumz et al, (79) } \\
\text { Beroukhim et al, (91) } \\
\text { Beroukhim et al, (91) }\end{array}$ \\
\hline Leukemia & $\begin{array}{l}3.596 \\
2.053 \\
-2.354 \\
-2.274\end{array}$ & $\begin{array}{l}2.40 \mathrm{E}-5 \\
4.10 \mathrm{E}-5 \\
1.21 \mathrm{E}-4 \\
1.22 \mathrm{E}-4\end{array}$ & $\begin{array}{r}6 \\
6 \\
14 \\
6\end{array}$ & $\begin{array}{l}22 \\
84 \\
39 \\
11\end{array}$ & $\begin{array}{l}\text { Andersson et al, (80) } \\
\text { Andersson et al, }(80) \\
\text { Rosenwald et al, (85) } \\
\text { Andersson et al, }(83)\end{array}$ \\
\hline Liver cancer & $\begin{array}{l}17.693 \\
6.620 \\
5.928\end{array}$ & $\begin{array}{l}1.42 \mathrm{E}-6 \\
9.20 \mathrm{E}-5 \\
1.78 \mathrm{E}-4\end{array}$ & $\begin{array}{l}10 \\
10 \\
10\end{array}$ & $\begin{array}{l}13 \\
17 \\
35\end{array}$ & $\begin{array}{l}\text { Wurmbach et al, (81) } \\
\text { Wurmbach et al, (81) } \\
\text { Wurmbach et al, (81) }\end{array}$ \\
\hline Lymphoma & $\begin{array}{l}5.390 \\
5.656 \\
5.045 \\
43.703 \\
8.586 \\
9.124\end{array}$ & $\begin{array}{l}8.61 \mathrm{E}-9 \\
6.66 \mathrm{E}-8 \\
4.51 \mathrm{E}-4 \\
1.40 \mathrm{E}-17 \\
9.08 \mathrm{E}-7 \\
3.89 \mathrm{E}-5\end{array}$ & $\begin{array}{r}14 \\
7 \\
6 \\
25 \\
25 \\
25\end{array}$ & $\begin{array}{r}38 \\
260 \\
5 \\
28 \\
32 \\
17\end{array}$ & $\begin{array}{l}\text { Rosenwald et al, (82) } \\
\text { Rosenwald et al, (83) } \\
\text { Storz et al, (84) } \\
\text { Basso et al, (85) } \\
\text { Basso et al, (85) } \\
\text { Basso et al, (85) }\end{array}$ \\
\hline Melanoma & 5.651 & $2.52 \mathrm{E}-4$ & 3 & 6 & Haqq et al, (86) \\
\hline Other cancer & & & & & \\
\hline Testicular seminoma & 2.614 & $5.49 \mathrm{E}-4$ & 3 & 3 & Skotheim et al, (87) \\
\hline Parathyroid adenoma & 2.434 & $1.73 \mathrm{E}-4$ & 5 & 35 & Morrison et al, (88) \\
\hline Sarcoma & 8.098 & $1.12 \mathrm{E}-4$ & 15 & 9 & Detwiller et al, (89) \\
\hline Embryonal carcinoma & 7.103 & $1.13 \mathrm{E}-7$ & 6 & 15 & Korkola et al, (90) \\
\hline Seminoma & 6.118 & $1.71 \mathrm{E}-6$ & 6 & 12 & Korkola et al, (90) \\
\hline Mixed germ cell tumor & 2.406 & $1.67 \mathrm{E}-6$ & 6 & 41 & Korkola et al, (90) \\
\hline
\end{tabular}

to induce IFN- $\alpha$ and CXCL10 in the CNS tumor microenvironment. In this experiment, Okada (61) successfully improved the survival of tumor-bearing mice without the generation of detectable autoimmunity. A phase I/II vaccination study based on Okada's concept is currently under way in patients with recurrent malignant glioma. Another obstacle for tumor antigen-specific T-cell immunity is the rapid down-regulation of chemokines, such as CXCL10, resulting in a negative feedback mechanism. To solve this issue, Kang et al introduced the CXCL10 gene into DC2.4 cells using a retroviral system, resulting in the secretion of functionally chemoattractive CXCL10. Findings by these authors have laid the foundation for a future clinical translation of the chemokine-based genetic modification of DCs to increase their vaccine potency (62). CXCL10 has also been determined to have synergistic effects with a deoxycytidine 
analog, gemcitabine, which inhibits the proliferation of endothelial cells, induces tumor cells apoptosis, and recruits lymphocytes to the tumor in murine models. Kang et al subsequently established an ideal model for the treatment of cancer by a combination of gene and chemokine therapy (63). A human study shows CXCL10 to be down-regulated in colorectal cancer (CRC) tissues with recurrence, indicating that CXCL10 may be utilized as a predictor of recurrence and as a prognostic indicator for survival in CRC patients (52).

Tumor-promoting effects. Contrary to tumor-limiting actions, CXCL10 exhibits tumor-promoting ability. Investigators have proposed that CXC chemokines and their receptors, particularly CXCR3 and its ligands CXCL10, CXCL9 and CXCL11, may be involved in tumor progression and metastasis through the overexpressions of CXCR3 in the tumor cells compared to the infiltrating immunocompetent cells, resulting in overresponsiveness to chemokines expressed either by tumors or inflammatory cells $(24,64,65)$. In human breast cancer cell lines MDA-MB-435 and MCF-7, Ras induces CXCL10 overexpression by way of Raf and PI3 kinase signaling pathways. Overexpressed CXCL10 binds to CXCR3 and down-regulates CXCR3-B, promoting breast cancer growth (46). CXCL10 has also been reported as an autocrine invasion factor in nasal natural killer/T-cell lymphoma (66), which promotes colon cancer metastasis (67), and tumorigenesis in basal cell carcinoma (14) and human glioma (44).

CXCL10 expression in human cancers from the Oncomine database. CXCL10 information was summarized using the publicized microarray database Oncomine 4.3 (https://www. oncomine.org/resource). The P-value cut-off was 0.001 , with a fold change threshold of 4. CXCL10 mRNA is up-regulated in the majority of human cancers, but is down-regulated in a limited number of cancers (68-90) (Table I).

\section{Conclusions}

Although CXCL10 was originally identified as a proinflammatory chemokine that plays a role in leukocyte trafficking, it has been found not to only activate T lymphocytes (Th1) (7), but also NK cells, inflammatory dentritic cells, most macrophages and B cells. CXCL10 is capable of homing to target/ threat regions. CXCL10 has multiple roles, such as modulating innate and adaptive immune response, regulating cell growth and angiostatic effects. CXCL10 induction is associated with numerous human disorders, and contributes to infectious diseases, chronic inflammatory and autoimmune diseases, and tumor formation. The features of CXCL10 make it a potential novel candidate for cancer target therapy. The relationship between the downstream and upstream signaling pathways should be investigated in order to develop CXCL10 as a novel therapeutic target in cancer and other human disorders.

\section{Acknowledgements}

This study was supported by the NIH/Fogarty International Center (FIC) post-doctoral training grant in Genomics and Hemo-globinopathies (NIH-FIC-1T90-HG004151-01) and NIH-RCMT (RR033062).

\section{References}

1. Moser B and Loetscher P: Lymphocyte traffic control by chemokines. Nat Immunol 2: 123-128, 2001.

2. Lee EY, Lee ZH and Song YW: CXCL10 and autoimmune diseases. Autoimmun Rev 8: 379-383, 2009.

3. Swaminathan GJ, Holloway DE, Colvin RA, et al: Crystal structures of oligomeric forms of the IP-10/CXCL10 chemokine. Structure 11: 521-532, 2003.

4. Zlotnik A and Yoshie O: Chemokines: a new classification system and their role in immunity. Immunity 12: 121-127, 2000.

5. Loetscher $\mathrm{P}$ and Clark-Lewis I: Agonistic and antagonistic activities of chemokines. J Leukoc Biol 69: 881-884, 2001.

6. Loetscher M, Gerber B, Loetscher P, et al: Chemokine receptor specific for IP10 and mig: structure, function, and expression in activated T-lymphocytes. J Exp Med 184: 963-969, 1996.

7. Sallusto F, Lenig D, Mackay CR and Lanzavecchia A: Flexible programs of chemokine receptor expression on human polarized T helper 1 and 2 lymphocytes. J Exp Med 187: 875-883, 1998.

8. Loetscher M, Loetscher P, Brass N, Meese E and Moser B: Lymphocyte-specific chemokine receptor CXCR3: regulation, chemokine binding and gene localization. Eur J Immunol 28: 3696-3705, 1998

9. Qin S, Rottman JB, Myers P, et al: The chemokine receptors CXCR3 and CCR5 mark subsets of T cells associated with certain inflammatory reactions. J Clin Invest 101: 746-754, 1998.

10. Cole KE, Strick CA, Paradis TJ, et al: Interferon-inducible $\mathrm{T}$ cell alpha chemoattractant (I-TAC): a novel non-ELR CXC chemokine with potent activity on activated T cells through selective high affinity binding to CXCR3. J Exp Med 187: 2009-2021, 1998.

11. Clark-Lewis I, Mattioli I, Gong JH and Loetscher P: Structurefunction relationship between the human chemokine receptor CXCR3 and its ligands. J Biol Chem 278: 289-295, 2003.

12. Dyer KD, Percopo CM, Fischer ER, Gabryszewski SJ and Rosenberg HF: Pneumoviruses infect eosinophils and elicit MyD88-dependent release of chemoattractant cytokines and interleukin-6. Blood 114: 2649-2656, 2009.

13. Luster AD and Ravetch JV: Biochemical characterization of a gamma interferon-inducible cytokine (IP-10). J Exp Med 166: 1084-1097, 1987.

14. Lo BK, Yu M, Zloty D, Cowan B, Shapiro J and McElwee KJ: CXCR3/ligands are significantly involved in the tumorigenesis of basal cell carcinomas. Am J Pathol 176: 2435-2446, 2010.

15. Bonecchi R, Bianchi G, Bordignon PP, et al: Differential expression of chemokine receptors and chemotactic responsiveness of type $1 \mathrm{~T}$ helper cells (Th1s) and Th2s. J Exp Med 187: 129-134, 1998.

16. Hancock WW, Gao W, Csizmadia V, Faia KL, Shemmeri N and Luster AD: Donor-derived IP-10 initiates development of acute allograft rejection. J Exp Med 193: 975-980, 2001.

17. Khan IA, MacLean JA, Lee FS, et al: IP-10 is critical for effector $\mathrm{T}$ cell trafficking and host survival in Toxoplasma gondii infection. Immunity 12: 483-494, 2000.

18. Kanda N, Shimizu T, Tada Y and Watanabe S: IL-18 enhances IFN-gamma-induced production of CXCL9, CXCL10, and CXCL11 in human keratinocytes. Eur J Immunol 37: 338-350, 2007.

19. Kanda $\mathrm{N}$ and Watanabe S: Prolactin enhances interferon-gamma induced production of CXC ligand 9 (CXCL9), CXCL10, and CXCL11 in human keratinocytes. Endocrinology 148: 2317-2325, 2007.

20. Mee JB, Johnson CM, Morar N, Burslem F and Groves RW: The psoriatic transcriptome closely resembles that induced by interleukin-1 in cultured keratinocytes: dominance of innate immune responses in psoriasis. Am J Pathol 171: 32-42, 2007.

21. Angiolillo AL, Sgadari C, Taub DD, et al: Human interferoninducible protein 10 is a potent inhibitor of angiogenesis in vivo. J Exp Med 182: 155-162, 1995.

22. Persano L, Crescenzi M and Indraccolo S: Anti-angiogenic gene therapy of cancer: current status and future prospects. Mol Aspects Med 28: 87-114, 2007.

23. Belperio JA, Keane MP, Arenberg DA, et al: CXC chemokines in angiogenesis. J Leukoc Biol 68: 1-8, 2000.

24. Monteagudo C, Martin JM, Jorda E and Llombart-Bosch A: CXCR3 chemokine receptor immunoreactivity in primary cutaneous malignant melanoma: correlation with clinicopathological prognostic factors. J Clin Pathol 60: 596-599, 2007. 
25. Furuya M, Suyama T, Usui H, et al: Up-regulation of CXC chemokines and their receptors: implications for proinflammatory microenvironments of ovarian carcinomas and endometriosis. Hum Pathol 38: 1676-1687, 2007.

26. Pellegrino A, Antonaci F, Russo F, et al: CXCR3-binding chemokines in multiple myeloma. Cancer Lett 207: 221-227, 2004.

27. Jones D, Benjamin RJ, Shahsafaei A and Dorfman DM: The chemokine receptor CXCR3 is expressed in a subset of B-cell lymphomas and is a marker of B-cell chronic lymphocytic leukemia. Blood 95: 627-632, 2000.

28. Farina C, Aloisi F and Meinl E: Astrocytes are active players in cerebral innate immunity. Trends Immunol 28: 138-145, 2007.

29. Vinet J, de Jong EK, Boddeke HW, et al: Expression of CXCL10 in cultured cortical neurons. J Neurochem 112: 703-714, 2009.

30. Van Weering HR, Boddeke HW, Vinet J, et al: CXCL10/CXCR3 signaling in glia cells differentially affects NMDA-induced cell death in CA and DG neurons of the mouse hippocampus. Hippocampus 21: 220-232, 2011.

31. Luster AD, Unkeless JC and Ravetch JV: Gamma-interferon transcriptionally regulates an early-response gene containing homology to platelet proteins. Nature 315: 672-676, 1985.

32. Luster AD, Jhanwar SC, Chaganti RS, Kersey JH and Ravetch JV: Interferon-inducible gene maps to a chromosomal band associated with a $(4 ; 11)$ translocation in acute leukemia cells. Proc Natl Acad Sci USA 84: 2868-2871, 1987.

33. Booth V, Keizer DW, Kamphuis MB, Clark-Lewis I and Sykes BD: The CXCR3 binding chemokine IP-10/CXCL10: structure and receptor interactions. Biochemistry 41: 10418-10425, 2002.

34. Campanella GS, Grimm J, Manice LA, et al: Oligomerization of CXCL10 is necessary for endothelial cell presentation and in vivo activity. J Immunol 177: 6991-6998, 2006.

35. Jabeen T, Leonard P, Jamaluddin H and Acharya KR: Structure of mouse IP-10, a chemokine. Acta Crystallogr D Biol Crystallogr 64: 611-619, 2008.

36. Colvin RA, Campanella GS, Sun J and Luster AD: Intracellular domains of CXCR3 that mediate CXCL9, CXCL10, and CXCL11 function. J Biol Chem 279: 30219-30227, 2004.

37. Enderlin M, Kleinmann EV, Struyf S, et al: TNF-alpha and the IFN-gamma-inducible protein 10 (IP-10/CXCL-10) delivered by parvoviral vectors act in synergy to induce antitumor effects in mouse glioblastoma. Cancer Gene Ther 16: 149-160, 2009.

38. Liu L, Callahan MK, Huang D and Ransohoff RM: Chemokine receptor CXCR3: an unexpected enigma. Curr Top Dev Biol 68: 149-181, 2005

39. Neville LF, Mathiak G and Bagasra O: The immunobiology of interferon-gamma inducible protein $10 \mathrm{kDa}$ (IP-10): a novel, pleiotropic member of the $\mathrm{C}-\mathrm{X}-\mathrm{C}$ chemokine superfamily. Cytokine Growth Factor Rev 8: 207-219, 1997.

40. Rice D and Barone S Jr: Critical periods of vulnerability for the developing nervous system: evidence from humans and anima models. Environ Health Perspect 108 (Suppl 3): 511-533, 2000.

41. Yang LL, Ping C, Luo S, et al: CXCL10 gene therapy efficiently inhibited the growth of cervical carcinoma based on the antiangiogenic and antiviral activity. Biotechnol Appl Biochem: Mar 3 , 2009 (Epub ahead of print).

42. Aksoy MO, Yang Y, Ji R, et al: CXCR3 surface expression in human airway epithelial cells: cell cycle dependence and effect on cell proliferation. Am J Physiol Lung Cell Mol Physiol 290: L909-L918, 2006.

43. Ji R, Lee CM, Gonzales LW, et al: Human type II pneumocyte chemotactic responses to CXCR3 activation are mediated by splice variant A. Am J Physiol Lung Cell Mol Physiol 294: L1187-L1196, 2008

44. Maru SV, Holloway KA, Flynn G, et al: Chemokine production and chemokine receptor expression by human glioma cells: role of CXCL10 in tumour cell proliferation. J Neuroimmunol 199: $35-45,2008$

45. Shen Q, Zhang R and Bhat NR: MAP kinase regulation of IP10/ CXCL10 chemokine gene expression in microglial cells. Brain Res 1086: 9-16, 2006.

46. Datta D, Flaxenburg JA, Laxmanan S, et al: Ras-induced modulation of CXCL10 and its receptor splice variant CXCR3-B in MDA-MB-435 and MCF-7 cells: relevance for the development of human breast cancer. Cancer Res 66: 9509-9518, 2006.

47. Giuliani N, Bonomini S, Romagnani P, et al: CXCR3 and its binding chemokines in myeloma cells: expression of isoforms and potential relationships with myeloma cell proliferation and survival. Haematologica 91: 1489-1497, 2006.
48. Kim S, Bakre M, Yin H and Varner JA: Inhibition of endothelial cell survival and angiogenesis by protein kinase A. J Clin Invest110: 933-941, 2002.

49. Sato E, Fujimoto $\mathrm{J}$ and Tamaya T: Expression of interferon-gamma-inducible protein 10 related to angiogenesis in uterine endometrial cancers. Oncology 73: 246-251, 2007.

50. Aronica SM, Raiber L, Hanzly M and Kisela C: Antitumor/ antiestrogenic effect of the chemokine interferon inducible protein 10 (IP-10) involves suppression of VEGF expression in mammary tissue. J Interferon Cytokine Res 29: 83-92, 2009.

51. Aronica SM, Fanti P, Kaminskaya K, et al: Estrogen disrupts chemokine-mediated chemokine release from mammary cells: implications for the interplay between estrogen and IP-10 in the regulation of mammary tumor formation. Breast Cancer Res Treat 84: 235-245, 2004

52. Jiang Z, Xu Y and Cai S: CXCL10 expression and prognostic significance in stage II and III colorectal cancer. Mol Biol Rep 37: 3029-3036, 2010.

53. Romagnani $P$, Lasagni L, Annunziato F, Serio $M$ and Romagnani S: CXC chemokines: the regulatory link between inflammation and angiogenesis. Trends Immunol 25: 201-209, 2004.

54. Shahabuddin S, Ji R, Wang P, et al: CXCR3 chemokine receptorinduced chemotaxis in human airway epithelial cells: role of p38 MAPK and PI3K signaling pathways. Am J Physiol Cell Physiol 291: C34-C39, 2006.

55. Han C, Fu J, Liu Z, Huang H, Luo L and Yin Z: Dipyrithione inhibits IFN-gamma-induced JAK/STAT1 signaling pathway activation and IP-10/CXCL10 expression in RAW264.7 cells. Inflamm Res 59: 809-816, 2010.

56. Nakamichi K, Inoue S, Takasaki T, Morimoto K and Kurane I: Rabies virus stimulates nitric oxide production and CXC chemokine ligand 10 expression in macrophages through activation of extracellular signal-regulated kinases 1 and 2. J Virol 78: 9376-9388, 2004.

57. Nakamichi K, Saiki M, Sawada M, et al: Rabies virus-induced activation of mitogen-activated protein kinase and NF-kappaB signaling pathways regulates expression of CXC and CC chemokine ligands in microglia. J Virol 79: 11801-11812, 2005.

58. Fujita M, Zhu X, Ueda R, et al: Effective immunotherapy against murine gliomas using type 1 polarizing dendritic cells significant roles of CXCL10. Cancer Res 69: 1587-1595, 2009.

59. Lu XL, Jiang XB, Liu RE and Zhang SM: The enhanced antiangiogenic and antitumor effects of combining flk1-based DNA vaccine and IP-10. Vaccine 26: 5352-5357, 2008.

60. Jiang XB, Lu XL, Hu P and Liu RE: Improved therapeutic efficacy using vaccination with glioma lysate-pulsed dendritic cells combined with IP-10 in murine glioma. Vaccine 27: 6210-6216, 2009

61. Okada H: Brain tumor immunotherapy with type-1 polarizing strategies. Ann NY Acad Sci 1174: 18-23, 2009.

62. Kang TH, Bae HC, Kim SH, et al: Modification of dendritic cells with interferon-gamma-inducible protein-10 gene to enhance vaccine potency. J Gene Med 11: 889-898, 2009.

63. Mei K, Wang L, Tian L, Yu J, Zhang Z and Wei Y: Antitumor efficacy of combination of interferon-gamma-inducible protein 10 gene with gemcitabine, a study in murine model. J Exp Clin Cancer Res 27: 63, 2008.

64. Balkwill F and Mantovani A: Inflammation and cancer: back to Virchow? Lancet 357: 539-545, 2001.

65. Oppenheim JJ, Murphy WJ, Chertox O, Schirrmacher V and Wang JM: Prospects for cytokine and chemokine biotherapy. Clin Cancer Res 3: 2682-2686, 1997.

66. Moriai S, Takahara M, Ogino T, et al: Production of interferon\{gamma\}-inducible protein-10 and its role as an autocrine invasion factor in nasal natural killer/T-cell lymphoma cells. Clin Cancer Res 15: 6771-6779, 2009.

67. Kawada K, Hosogi H, Sonoshita M, et al: Chemokine receptor CXCR3 promotes colon cancer metastasis to lymph nodes. Oncogene 26: 4679-4688, 2007.

68. Sanchez-Carbayo M, Socci ND, Lozano J, Saint F and CordonCardo C: Defining molecular profiles of poor outcome in patients with invasive bladder cancer using oligonucleotide microarrays. J Clin Oncol 24: 778-789, 2006.

69. Sun L, Hui AM, Su Q, et al: Neuronal and glioma-derived stem cell factor induces angiogenesis within the brain. Cancer Cell 9: 287-300, 2006

70. Lee J, Kotliarova S, Kotliarov Y, et al: Tumor stem cells derived from glioblastomas cultured in bFGF and EGF more closely mirror the phenotype and genotype of primary tumors than do serum-cultured cell lines. Cancer Cell 9: 391-403, 2006. 
71. Richardson AL, Wang ZC, De Nicolo A, et al: X chromosomal abnormalities in basal-like human breast cancer. Cancer Cell 9: 121-132, 2006.

72. Karnoub AE, Dash AB, Vo AP, et al: Mesenchymal stem cells within tumour stroma promote breast cancer metastasis. Nature 449: 557-563, 2007.

73. Pyeon D, Newton MA, Lambert PF, et al: Fundamental differences in cell cycle deregulation in human papillomaviruspositive and human papillomavirus-negative head/neck and cervical cancers. Cancer Res 67: 4605-4619, 2007.

74. Ki DH, Jeung $\mathrm{HC}$, Park $\mathrm{CH}$, et al: Whole genome analysis for liver metastasis gene signatures in colorectal cancer. Int J Cancer 121: 2005-2012, 2007.

75. Ginos MA, Page GP, Michalowicz BS, et al: Identification of a gene expression signature associated with recurrent disease in squamous cell carcinoma of the head and neck. Cancer Res 64 : 55-63, 2004.

76. Talbot SG, Estilo C, Maghami E, et al: Gene expression profiling allows distinction between primary and metastatic squamous cell carcinomas in the lung. Cancer Res 65: 3063-3071, 2005.

77. Yusenko MV, Kuiper RP, Boethe T, Ljungberg B, van Kessel AG and Kovacs G: High-resolution DNA copy number and gene expression analyses distinguish chromophobe renal cell carcinomas and renal oncocytomas. BMC Cancer 9: 152, 2009.

78. Gumz ML, Zou H, Kreinest PA, et al: Secreted frizzled-related protein 1 loss contributes to tumor phenotype of clear cell renal cell carcinoma. Clin Cancer Res 13: 4740-4749, 2007.

79. Andersson A, Ritz C, Lindgren D, et al: Microarray-based classification of a consecutive series of 121 childhood acute leukemias: prediction of leukemic and genetic subtype as well as of minimal residual disease status. Leukemia 21: 1198-1203, 2007.

80. Wurmbach E, Chen YB, Khitrov G, et al: Genome-wide molecular profiles of $\mathrm{HCV}$-induced dysplasia and hepatocellular carcinoma. Hepatology 45: 938-947, 2007.

81. Rosenwald A, Alizadeh AA, Widhopf G, et al: Relation of gene expression phenotype to immunoglobulin mutation genotype in B cell chronic lymphocytic leukemia. J Exp Med 194: 1639-1647, 2001
82. Rosenwald A, Wright G, Chan WC, et al: The use of molecular profiling to predict survival after chemotherapy for diffuse large-B-cell lymphoma. N Engl J Med 346: 1937-1947, 2002.

83. Storz MN, van de Rijn M, Kim YH, Mraz-Gernhard S, Hoppe RT and Kohler S: Gene expression profiles of cutaneous B cell lymphoma. J Invest Dermatol 120: 865-870, 2003.

84. Basso K, Margolin AA, Stolovitzky G, Klein U, Dalla-Favera R and Califano A: Reverse engineering of regulatory networks in human B cells. Nat Genet 37: 382-390, 2005.

85. Haqq C, Nosrati M, Sudilovsky D, et al: The gene expression signatures of melanoma progression. Proc Natl Acad Sci USA 102: 6092-6097, 2005.

86. Skotheim RI, Lind GE, Monni O, et al: Differentiation of human embryonal carcinomas in vitro and in vivo reveals expression profiles relevant to normal development. Cancer Res 65 5588-5598, 2005.

87. Morrison C, Farrar W, Kneile J, et al: Molecular classification of parathyroid neoplasia by gene expression profiling. Am J Pathol 165: 565-576, 2004.

88. Detwiller KY, Fernando NT, Segal NH, Ryeom SW, D'Amore PA and Yoon SS: Analysis of hypoxia-related gene expression in sarcomas and effect of hypoxia on RNA interference of vascular endothelial cell growth factor A. Cancer Res 65: 5881-5889, 2005.

89. Korkola JE, Houldsworth J, Chadalavada RS, et al: Downregulation of stem cell genes, including those in a $200-\mathrm{kb}$ gene cluster at $12 \mathrm{p} 13.31$, is associated with in vivo differentiation of human male germ cell tumors. Cancer Res 66: 820-827, 2006.

90. Beroukhim R, Brunet JP, Di Napoli A, et al: Patterns of gene expression and copy-number alterations in von-hippel lindau disease-associated and sporadic clear cell carcinoma of the kidney. Cancer Res 69: 4674-4681, 2009. 